\title{
A comparison of the visual status of dyslexic and non-dyslexic schoolchildren in Durban, South Africa
}

\author{
Wajuihian $\mathrm{SO}^{\dagger}$ and Naidoo $\mathrm{KS}^{\ddagger}$
}

${ }^{\dagger}$ African Vision Research Institute (AVRI) University of KwaZulu-Natal, Private Bag X 54001, Durban, 4000 South Africa

\$International Center for Eye Care Education 272, Umbilo Road, Durban, 4001 South Africa

<swajuihian@mweb.co.za>

Received 10 August 2010; revised version accepted 24 February 2011

\section{Abstract}

Background: Reading difficulties constitute an impediment to the learning process and in the educational achievement of a child. Consequently, several studies examined the visual status of dyslexic children in the Caucasian populations. Such studies are lacking in the African populations. Aim: To determine the prevalence of vision defects and investigate if there is an association between dyslexia and vision in a South African population of dyslexic school children. Methods: This comparative study assessed the visual function of 62 children (31 dyslexic and 31 normally-reading children), mean age $13 \pm 1.42$ years and $11.90 \pm 0.93$ years respectively. The participants were matched for gender, race and socio-economic status. The visual functions evaluated and the techniques used were: visual acuity (LogMAR acuity chart), refraction (static retinoscopy), ocular alignment (cover test) near point of convergence (RAF rule), accommodation facility ( \pm 2 D flipper lenses), amplitude of accommodation (push-up method) relative accommodation (trial lenses) accommodation posture (monocular estimation technique) and vergence reserves (prism bars). Results: In the following, results are pro- vided for the dyslexic versus control: Refractive errors: (hyperopia $6.5 \%$ vs 3\%,) (myopia 6.5\% vs $6.5 \%$ ), (astigmatism $10 \%$ vs $13 \%$ ), (anisometropia $6.5 \%$ vs $6.5 \%$ ) (amblyopia $6.5 \%$ vs $0 \%$ ), (remote NPC $33 \%$ vs $48 \%$ ) (esophoria at near 3\% vs $0 \%$ ) (exophoria at near 9.5\% vs 0\%), (accommodative infacility at near $54 \%$ vs $33 \%$ ), lag of accommodation $39.28 \%$ vs $41,93 \%$, (poor positive fusional amplitude at near, $25 \%$ vs $16 \%$ ). Only the binocular accommodative facility at near was significantly associated with dyslexia $(p=0.027)$. Conclusion: The prevalence of vision defects was similar between the dyslexic and non-dyslexic participants, which suggest that an association between dyslexia and vision variables investigated, cannot be inferred. This study provides a research perspective on the prevalence of vision defects in a Black South African population of dyslexic children and has clinical relevance and implications for the assessment, detection and management of vision anomalies in dyslexic schoolchildren. ( $S$ Afr Optom 2011 70(1) 29-43)

Key words: Visual acuity in dyslexia, refractive errors in dyslexia, vergence and accommodation functions, heterophoria fusional reserves and dyslexia

BSc (Hons) Optom OD (Benin) MOptom (UKZN) PGCertMod L/Vision (City Univ London)

BSc BOptom (UDW) MPH (Temple) OD (PCO) PhD (UNSW)

*This paper forms part of research for the degree Master in Optometry (MOptom) at the University of KwaZulu-Natal undertaken by Samuel Wajuihian with the supervision of Professor Kovin Naidoo. 


\section{Introduction}

Dyslexia is an unexpected, specific difficulty in reading in children and adults with adequate intelligence, motivation, socio-cultural opportunity, education and absence of emotional disorders ${ }^{1}$. Reading, the visual process of deriving meaning from written text ${ }^{2}$ is fundamental to learning. Between $75 \%$ and $90 \%$ of what a child learns is mediated through the visual pathways and early detection and treatment of vision anomalies reduces the risk of long-term visual problems ${ }^{3}$. Optometrists often receive referrals from teachers, psychologists and other professionals who seek advice about whether vision problems may contribute to or be responsible for a child's poor academic performance. Consequently, several studies ${ }^{4-15}$ have been conducted on various aspects of visual functions in dyslexia. However, these studies were limited to Caucasians and the results were inconsistent (see Wajuihian and Naidoo for a detailed review) $)^{16}$. For example, the prevalence of reduced visual acuity (VA) has been reported to be worse in the dyslexic in certain studies $4,8,9,13$ similar in dyslexic and control reported by Buzzelli ${ }^{5}$ and Goulandris 6 , while Kapoula et $a l^{10}$ and Buccis et al ${ }^{12}$ found normal visual acuity $(\geq 6 / 9)$ in all participants. Evans et $a l^{4}$ and Ygge et $a l^{13}$ reported the prevalence of total refractive errors to be similar in both the dyslexic and control groups. The prevalence of astigmatism was greater in the dyslexic group compared to the control group reported by Latvala $e t a l^{8}$ and Yggee et al13. Latvala et $a l^{8}$ also reported the prevalence of amblyopia in the dyslexic group to be $3.6 \%$, whereas no participant in the control group was amblyopic while the prevalence of anisometropia was greater in the control than in the dyslexic group 8,13 . Latvala et $a l^{8}$ and Kapoula et a ${ }^{10}$ reported the prevalence of remote NPC to be higher in the dyslexic than in the non-dyslexic group. For heterophoria, Latvala $e^{2} a^{8}$ found no statistically significant difference between the two groups $(p=0.59)$ for exophoria and $(p=0.46)$ for esophoria. Similarly, Buccis et $a l^{12}$ measured heterophoria at far and near using the cover-uncover test and found no statistically significant difference between the two groups $(p=0.2)$. For accommodative functions, Evans et al7 reported that amplitude of accommodation was significantly reduced in the dyslexic group compared to the control group whereas Ygge et al ${ }^{11}$ and Goulandris et al ${ }^{6}$ found that the two groups performed similarly. Evans et $a l^{7}$ found the dyslexic group to be slower than the control group when performing the accommodative facility (AF) test. In contrast, Buzzelli ${ }^{5}$ found that the dyslexic subjects showed better AF than the control group, although there was no statistically significant relationship between the two groups ( $p=0.629)$. Evans et $a l^{7}$ reported no statistically significant difference between the dyslexic and the control groups $(p>0.68$, unpaired $t$-test) in accommodation lag. The incidence of fusional amplitude at near was higher in the dyslexic $(7.5 \%)$ than in control $(6.1 \%)$ group as reported by Latvala et $a l^{8}$ and at distance, they found fusional amplitude to be higher in the control $(12.2 \%)$ than in the dyslexic (9.4\%) group. Ygge et al ${ }^{11}$ and Goulandris et $a l^{6}$ found that the two groups performed similarly in fusional reserves at both distance and near whereas Evans et al $^{7}$ reported that both negative and positive fusional reserves were reduced in the dyslexic relative to the control group. Stein et all5 reported that $67 \%$ of the 36 dyslexic participants in their study had abnormal vergence control.

Given the scarcity of optometric literature and research on visual status of dyslexic schoolchildren in South Africa, the primary aim of this study, therefore, was to determine the prevalence of visual defects (visual acuity, refraction, binocular functions, and ocular pathology) in a population of Black African dyslexic schoolchildren in South Africa. The secondary aim was to investigate if there is an association between visual factors and dyslexia in an African population by comparing the visual characteristics of the dyslexic participants from a school for children with learning difficulties with a gender, race and socio-economic status matched control group comprising non-dyslexic schoolchildren from the mainstream school. We hypothesized that the dyslexic participant did not have a higher prevalence of vision defects than the control group and that there was no statistically significant association between dyslexia and vision variables. However, if an association between dyslexia and visual variables exist, a higher prevalence of vision defects in dyslexic than in the control group would be expected.

\section{Methods}

The study was approved by the University of KwaZulu Natal's Faculty of Health Sciences Ethics Committee. Written informed consents for access to the schools (mainstream and special school) were ob- 
tained from the Department of Education and from the principals of the schools. Due to the difficulty in reaching the learners' parents, the school principals consented on behalf of the parents for the learners to participate in the study. All participants agreed to participate in the study after the nature of the study was explained to them.

\section{Study design}

This study was designed to provide empirical (quantitative) information to enable a comparison of the visual characteristics of dyslexic children (experimental group) and non-dyslexic children (control group). In South Africa, when children with learning difficulties are identified, they are evaluated and taken out of the mainstream school and are given special tuition. Participants from both groups were matched in gender, race and socio-economic status and were selected by convenient sampling. Although this sampling method has been employed in several studies on dyslexic populations ${ }^{5,6,10-13,15}$ the decision to use it in the present study was because at the time of the study, there was only one school that catered for dyslexic Black learners in the Durban area.

The inclusion and exclusion criteria were in accordance with other studies on dyslexic population $5,6,7,13$. The participants from the dyslexic group had to meet the following criteria: (i) an average or above average intelligence quotient (that is, $>95$ ) (ii) two grades or more below the grade level expected considering their chronological age, and (iii) evidence that child has not been absent from school for more than $10 \%$ of the attendance days. Learners with known systemic illnesses, any emotional disorders and those on medication were excluded from the study. The inclusion and exclusion criteria for the control group were similar to the dyslexic group except that the non-dyslexic participants did not have any reading problems and were attending a mainstream school. All the information regarding the inclusion and exclusion criteria was obtained from the learners' file as reported by the school psychologist.

The study populations comprised children attending a school for children with learning difficulties from which the dyslexic children were selected whereas the control group consisted of children attending a mainstream school in Durban. The participants from the dyslexic group were selected from
Khulangolwazi School for children with learning difficulties in Clairwood, South of Durban. Learners attending this school were referred from different schools around Durban, South Africa. The dyslexic participants consisted of 31 children ( 15 boys and 16 girls) and were in grades four through seven. Psychoeducational evaluation and classification of learners as being dyslexic was not part of this study and was not performed. The dyslexic participants were selected based on the school psychologist's diagnosis. Because the number of dyslexic learners were few it was difficult to recruit the targeted number of 100 dyslexic participants for the study, so only 31 was used but sample sizes for studies conducted on dyslexic population are typically small and the average of ten studies $^{4-8,10-13,15}$ on dyslexic participants was 46 .

Participants for the control group comprised 31 (15 boys and 16 girls) children from a mainstream school in Durban (Addington Primary School) and their grades ranged from four to seven. All participants in this study were Black South Africans.

\section{Materials and procedure}

Each school principal provided a room at the school venue where all procedures were conducted. All procedures were conducted in the mornings as it was expected that better responses could be obtained when the children were not tired. The rationale and technique for every procedure was fully explained to each participant and a trial reading was taken to ensure that all instructions given were understood. The first author collected all data and each examination took an average of thirty minutes to complete with rest periods of up to 10 minutes as necessary.

The instruments and the procedures used in this study follows the techniques described in standard optometric texts ${ }^{17-20}$ and was used in studies reviewed $^{4-15}$ on dyslexic populations. The following tests were performed.

Visual acuity was assessed using the Logarithm of Minimum Angle of Resolution (LogMAR) chart at both distance and near. Refractive errors were determined objectively using the streak retinoscope with a $+1.50 \mathrm{D}$ fogging lens (for an arm's length of approximately $67 \mathrm{~cm}$ ) while the subject fixated a $6 / 60$ (to maintain fixation) optotype on the distance visual acuity chart ${ }^{17-20}$. Cycloplegic refraction were not used due to medical-ethical reasons and the fact that 
static retinoscopy with fogging lenses usually enables adequate control of accommodation ${ }^{21}$. The near point of convergence (NPC) was measured using the Royal Air Force (RAF) rule ${ }^{17,22}$. The final break and recovery points recorded were the average of three tests measurements in order to detect fatigue, which may indicate poor convergence ${ }^{22,23}$ and the objective reading was recorded for analysis. Heterophoria was assessed using the cover test at 0.4 and 6 meters $^{17-20}$. As used in other studies $7,8.17-20$, the Maddox Wing was used to assess near phoria under normal room illumination and this results were used to analyze near heterophoria. However, the use of cover test for both distance and near would probably have allowed for standardization. The amplitude of accommodation was measured monocularly using Donder's pushup method with a Royal Air force (RAF) near point rule ${ }^{17-20}$. The accommodation facility (AF) was assessed binocularly using \pm 2 D lens flippers ${ }^{17-20}$. Accuracy of accommodation was evaluated using the monocular estimation method (MEM) in normal room illumination ${ }^{17-20}$. The relative accommodation (PRA and NRA) was assessed using trial lenses ${ }^{17-20}$. Ocular health was evaluated using a direct ophthalmoscope ${ }^{17-20}$. The fusional reserves (fusional vergence) measures the amount of fusion (fusional amplitude) ${ }^{24}$ the individual has in reserve to compensate for a phoria and provides information about a patient's ability to maintain comfortable binocular vision ${ }^{23}$. The fusional reserves were assessed at 6 meters (test target 6/9 letter line) and at $40 \mathrm{~cm}$ (N5 text) using prism bars without suppression control. The break and recovery points were determined subjectively from the child's report of blur, break and recovery and objectively by observing the subjects eye movements. The objective findings were used for analysis ${ }^{25-26}$.

\section{Data analysis}

The data was analyzed using the Statistical Package for Social Sciences (SSPS). Means and standard deviation were calculated for descriptive and comparative purposes. For comparison between the means of the two groups, all data was subjected to a two-sample $t$ test, unpaired (2-tailed). The level of significance considered to support or reject our hypothesis was taken as $p<0.05$. The diagnostic criteria for normal/ abnormal response for each test were in relation to expected values for the age group and as used in other studies (Table 1). Participants who did not meet the pass criteria for any of the test variables were referred to their optometrists for further evaluation.

\section{Results}

The data for the prevalence of visual acuity, refractive errors, near point of convergence, accommodation functions, heterophoria, fusional amplitude at

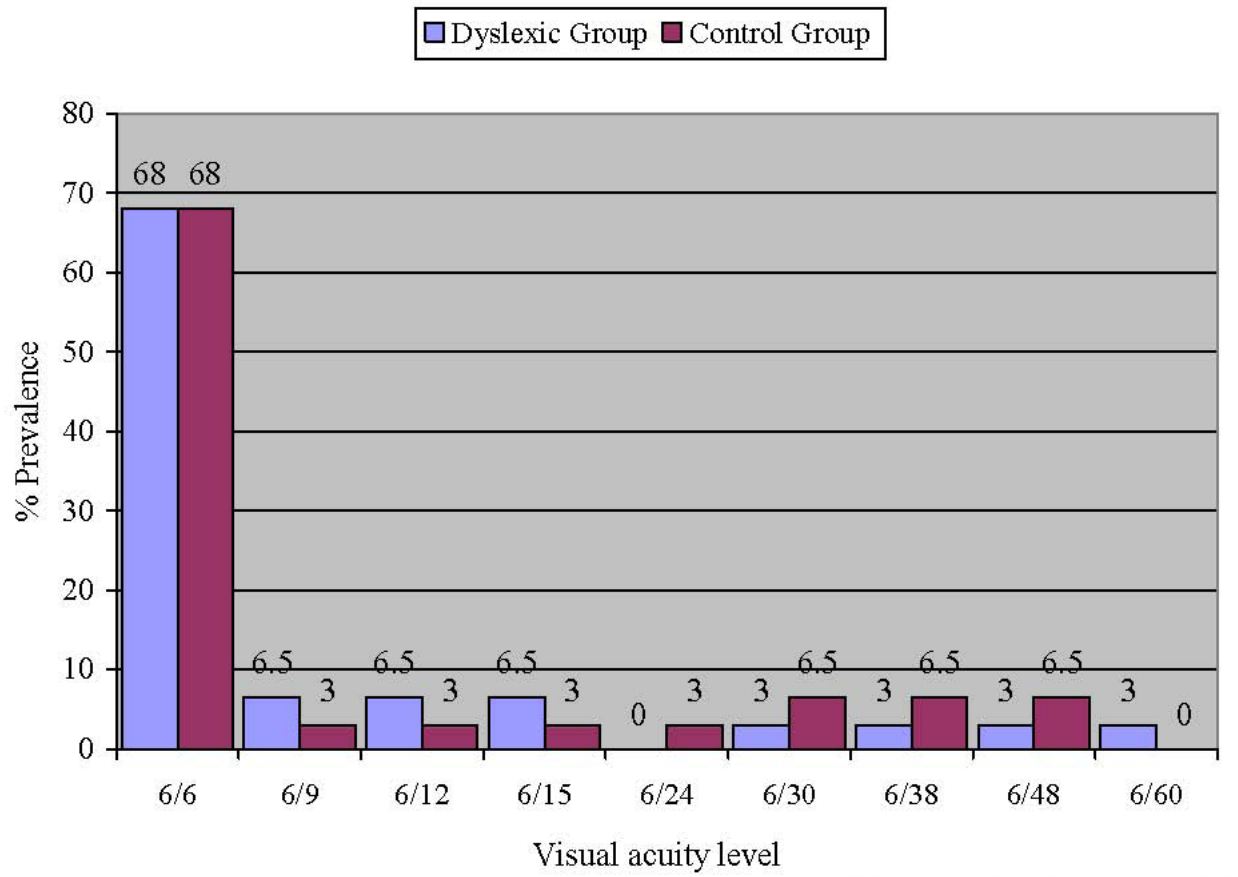

Figure 1. Comparison of percentage prevalence of visual acuity in dyslexic and control groups. Compared to the other acuity levels, the distribution of VA 6/6 (68\%) was the highest in both groups followed by VA $<6 / 9(32 \%)$ 
Table 1. The diagnostic criteria for each test variable.

\begin{tabular}{|c|c|}
\hline Variable & Diagnostic Criteria \\
\hline Visual Acuity ${ }^{27}$ & $6 / 9$ \\
\hline \multicolumn{2}{|l|}{ Refractive Errors ${ }^{27,28}$} \\
\hline Hyperopia & $\geq 0.75$ \\
\hline Myopia & $\geq-0.50$ \\
\hline Astigmatism & $\geq-0.75$ \\
\hline Anisometropia & $\geq 0.75$ between both eyes \\
\hline Emmetropia & $<-0.50<+1.00<-0.75 \mathrm{DCyl}$ \\
\hline Near Point of Convergence ${ }^{22,29}$ & $\geq 10 \mathrm{~cm}$ \\
\hline Accuracy of Accomm ${ }^{28}$ & Lag: $\geq 0.75$. Lead: any minus finding \\
\hline Accommodative Infacility $^{30}$ & $\begin{array}{l}>7 \mathrm{cpm} \text { in response to } \pm 2 \text { flipper lenses } \\
\text { binocularly at near }\end{array}$ \\
\hline Amplitude of Accommodation ${ }^{18}$ & $\begin{array}{l}\text { AA below the expected value for the patients' } \\
\text { age for minimum amplitude (using Hofsetter's } \\
\text { formula) ( } 15-0.25 \text { age). }\end{array}$ \\
\hline Relative Accommodation ${ }^{18,31}$ & \pm 2 \\
\hline Heterophoria Distance and Near ${ }^{18,32,33}$ & $\begin{array}{l}\geq 6 \text { pd exo or } 4 \text { pd esophoria } \geq 6 \text { pd exophoria } \\
\text { or } 4 \text { pd esophoria. }\end{array}$ \\
\hline Fusional Reserves Near ${ }^{18,23,34}$ & $\begin{array}{l}\text { BI: Blur } 14 \pm 4 \text {, Break } 12 \pm 5 \text {, Recovery } 7 \pm 4 \text {. } \\
\text { BO: Blur } 22 \pm 8 \text {, Break } 23 \pm 8 \text {, Recovery } \\
16 \pm 6 \text {. }\end{array}$ \\
\hline $\begin{array}{l}\text { Fusional amplitude (base out break) at } \\
\text { near }^{22,24}\end{array}$ & $30-40 \mathrm{pd}$ \\
\hline
\end{tabular}

near are presented in histograms (Figures 1 to 3 ). If an association between dyslexia and visual functions exists, a higher prevalence of vision defects in dyslexic than in the control group would be expected.

\section{Visual Acuity (VA)}

As shown in Figure 1, the distribution of distance $\mathrm{VA}<6 / 9(32 \%)$ as well as the distribution of $6 / 6$ $(68 \%)$ visual acuity was similar in both groups. The mean distance VA in the dyslexic group for the RE was $0.17 \pm 0.31$ (range 0 to $0.10 \operatorname{LogMAR}$ ) and the mean distance VA for the LE was $0.20 \pm 0.33$ (range 0 to 0.10 ). The mean distance VA in the control group for the RE and LE was the same: $0.00 \pm 0.24$ (range 0 to 0.90 ). However, the mean difference between the two groups was not statistically significant (RE, $p=0.29$, LE, $p=0.23$ ). All the participants had normal near visual acuity $(0.37 \mathrm{M})$ except for the two participants who had cataracts and both had significantly low VA (1.25 M both).

\section{Refractive Errors ( $R E$ )}

Refraction data for two children from the dyslexic group who had cataracts could not be obtained due to poor reflexes and were excluded in the analysis. The prevalence of refractive errors (23\% dyslexic, $22.5 \%$ 


\section{$\square$ Dyslexia $\square$ Control}

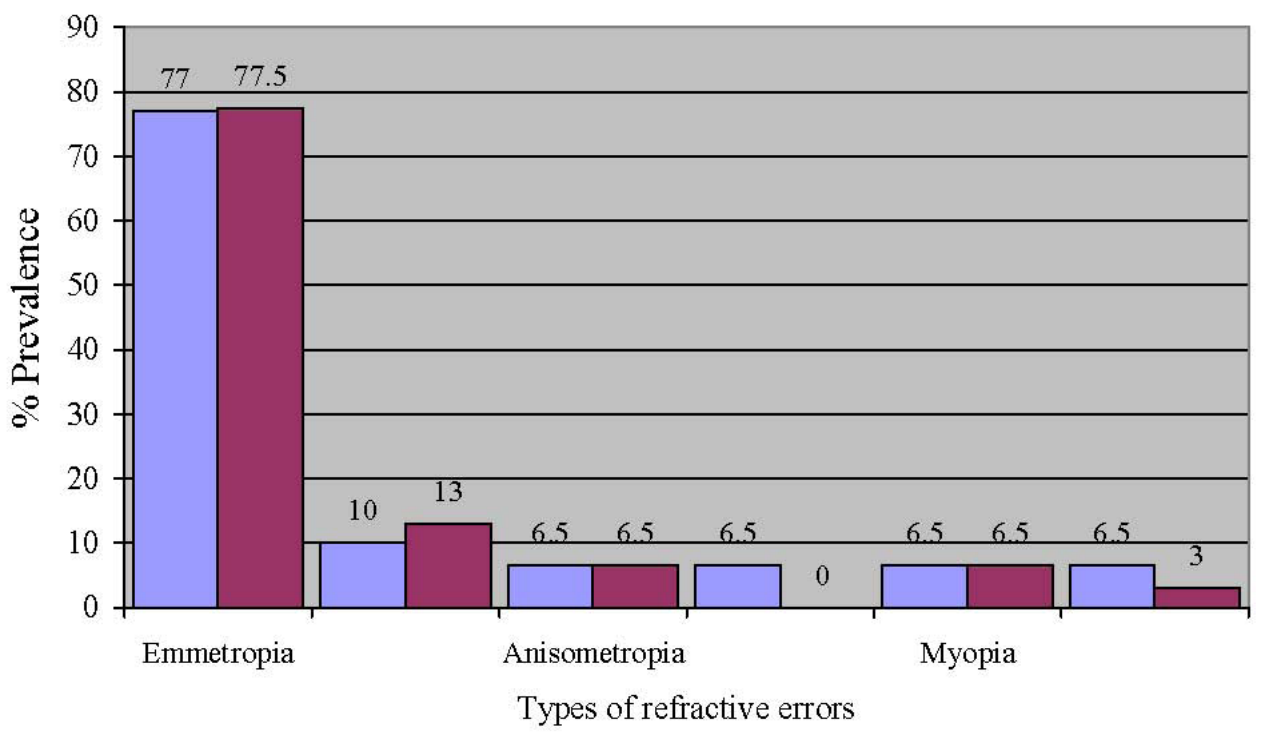

Figure 2. Comparison of percentage prevalence of refractive errors in dyslexic and control groups. The prevalence of emmetropia was the highest and was similar in both groups, followed by astigmatism.

control) was similar in both groups (Figure 2). For the dyslexic group, the mean refractive error for the $\mathrm{RE}$ was $+0.86 \pm 0.98 \mathrm{D}$ (range -1.25 to +5.00$)$. The mean for the $\mathrm{LE}$ was $+0.57 \pm 1.01 \mathrm{D}$ (range -1.50 to 4.00).

For the control group, the mean refractive error for the right eye was $+0.70 \pm 1.03 \mathrm{D}$ (range -3.50 to 3.50 ) and for the LE was $+0.49 \pm 1.09 \mathrm{D}$ (range -3.50 to 3.50 ). The mean difference between the two groups was not statistically significant (RE, $p=0.66$, $\mathrm{LE}, p=0.09)$. The distribution of the different types of refractive errors is shown in Figure 2.

\section{Near Point of Convergence (NPC)}

One participant from the dyslexic group complained of being tired and did not participate and was excluded. As shown in Figure 3, the prevalence of remote NPC (48\%, 15 participants) was higher in the control group than in the dyslexic group $(33 \%, 10$ participants). The mean NPC break for the dyslexic group was $8.90 \pm 5.03 \mathrm{~cm}$ (range 5 to 26) while the mean NPC break for the control group was $12.60 \pm$ $8.70 \mathrm{~cm}$ (range 4 to 34 ). The mean NPC recovery for the dyslexic group was $14 \pm 5.88 \mathrm{~cm}$ (range 6 to 28 ) and for the control group was $22 \pm 8.20 \mathrm{~cm}$ (range 8 to 38 ). There was a statistically significant difference between the two groups in NPC break and recovery (break, $p=0.049$, recovery $p=0.06$ ).

\section{Heterophoria}

Four participants from each group could not complete the test because they left to attend class lessons. In the dyslexic group, no participant manifested with phoria at distance. At near, one participant (3\%) had an esophoria $\geq 4$ prism diopters (pd), one participant $(3 \%)$ had an esophoria of $3 \mathrm{pd}$, two participants $(6.5 \%)$ had exophorias $\geq 4 \mathrm{pd}$, one participant $(3 \%)$ had an exophoria $\geq 8 \mathrm{pd}$ and two participants $(6.5 \%)$ had exophoria of $6 \mathrm{pd}$. In the control group, at both distance and near, no subject had phoria of $>2 \mathrm{pd}$. The mean for near exophoria in the dyslexic group was $1.63 \pm 2.62 \mathrm{pd}$ (range 0 to 10 ) and was $1.80 \pm$ $0.42 \mathrm{pd}$ (range 1 to 2 ) for the control group. The mean esophoria at near for the dyslexic group was $3.50 \pm$ $0.70 \mathrm{pd}$ (range 3 to 4 ) and for the control group was 2 \pm 0 (range 2 to 2 ). There was no statistically significant difference between the two groups in heterophoria (near exophoria, $p=0.59$, near esophoria, $p=0.46$ ).

\section{Accommodation Functions}

For amplitude of accommodation, one participant from the dyslexic group had a difference of four diopters between the two eyes. The amplitude of accommodation for two participants who had latent hyperopia in the dyslexic group was low (6 D and $8 \mathrm{D})$ as compared to age minimum amplitude of accommodation of $11.75 \mathrm{D}$. The amplitude of accommodation for two participants who had cataracts was excluded from the analysis. 
Only the data for the monocular amplitude was analyzed. In the dyslexic group, the mean AA (right eye) was $11.98 \pm 2.34 \mathrm{D}$ (range 8 to 20 ) and the mean for the LE was $12.14 \pm 2.15 \mathrm{D}$ (range 8 to 20 ). In the control group, the mean AA for the RE was $12.87 \pm$ $1.08 \mathrm{D}$ (range 10 to 15 ) and for the left eye was 12.87 $\pm 1.16 \mathrm{D}$ (range from 10 to 15 ). There was no statistically significant difference between the two groups $(\mathrm{RE} p=0.07)(\mathrm{LE} p=0.22)$.

For accommodative facility (AF), three participants from the dyslexic group and four from the control could not complete the test because they indicated that they were tired. The prevalence of poor accommodation facility (Figure 3) was higher in the dyslexic group (54\%, 15 participants) than in the control group (33\%, 9 participants) (Figure 3). In the dyslexic group, the mean AF was $6.86 \pm 2.74 \mathrm{cpm}$ (range 2 to 12). In the control group, the mean AF was $8.85 \pm$ $3.69 \mathrm{cpm}$ (range 2 to 21 ) and there was a statistically significant difference between the groups $(p=0.03)$.

For accuracy of accommodations (AL), three participants from the dyslexic group could not continue with this test because they left to attend class activities while three from the control group sought permission to be out of the testing room at that point. These participants were excluded in the analysis. As shown in Figure 3, the prevalence of lag of accommodation (used to assess AL) was higher (42\%, 13 participants) in the control group compared to the dyslexic group (39\%, 11 participants) (Figure 3).

In the dyslexic group, the mean AL for the RE was $0.91 \pm 0.38 \mathrm{D}$ (range 0 to 2 ) and the mean AL for the $\mathrm{LE}$ was $0.85 \pm 0.36 \mathrm{D}$ (range -0.50 to 1.25 ). In the control group, the mean AL for the RE was $0.92 \pm$ $0.57 \mathrm{D}$ (range -0.50 to 2 ) and the mean $\mathrm{AL}$ for the left eye was $0.91 \mathrm{SD} \pm 0.48 \mathrm{D}$ (range -0.50 to 2 ) and there was no statistically significant difference (RE, $p=0.83$, and LE, $p=0.61$ ).

For relative accommodation (NRA, PRA), the mean PRA was $-6.23 \pm 1.17 \mathrm{D}$ (range -9 to $-4 \mathrm{D}$ ) the dyslexic group and was $-6.06 \pm 0.63 \mathrm{D}$ (range -7 to $-5 \mathrm{D})$ for the control group. The mean NRA was $3.22 \pm 0.79 \mathrm{D}$ (range 2 to $6 \mathrm{D}$ ) for the dyslexic group and was $3.11 \pm 0.47 \mathrm{D}$ (range 2 to 4.50 ) for the control group. There was no statistically significant difference between the two groups in relative accommodation (PRA, $p=0.51$, NRA, $p=0.68$ ). The mean values for relative accommodation in this study were unexpectedly large.

\section{Ocular pathology}

Two participants $(6.5 \%)$ in the dyslexic group had cataracts on both eyes. No ocular pathology was detected in the control group.

\section{Fusional Reserves}

The participants from both groups either could not report or understand blur so the results for breaks and recoveries were used to analyze vergence function. Two participants from the dyslexic group could not complete all aspects of the fusional reserves assessment because they were tired. These participants were excluded in the analysis.

The mean base in to break at distance (BIBD) for the dyslexic group was $14.69 \pm 6.83 \mathrm{pd}$ (range: 4 to 40 ) and $16 \pm 3.50 \mathrm{pd}$ (10 to 22 ) for the control group. There was no statistically significant differences between both groups $(p=0.46)$. The mean base in to recovery at distance (BIRD) for the dyslexic group was $11.72 \pm 6.20 \mathrm{pd}$ (range 2 to 35 ) and $12.80 \pm 3.17 \mathrm{pd}$ (range 8 to 20) for the control group. There was no statistically significant difference between the groups ( $p=0.49$ ).

The mean base in to break at near ( BIBN) for the dyslexic group was $11.85 \pm 5.14 \mathrm{pd}$ (range 2 to 25 ) and $12.83 \pm 3.13$ (range 6 to 18) for the control group. There was no statistically significant difference between both groups $(p=0.29)$. The mean base in to recovery at near for the dyslexic group was $8.72 \pm 4.78$ pd (range 1 to 20) and $10.32 \pm 3.35$ pd (range 4 to 15) for the control group. There was no statistically significant difference between the groups $(p=0.17)$.

The mean base out to break at distance (BOBD) for the dyslexic group was $27.06 \pm 9.25 \mathrm{pd}$ (range 10 to 40 ) and $24.16 \pm 9.75$ pd (range 10 to 40 ) for the control group. There was no statistically significant difference between the groups $(p=0.24)$. For the base out to recovery at distance (BORD) four participants from the control group could not report the recovery point and two participants from the dyslexic group could not complete the test. The mean BORD for the dyslexic group was $18.76 \pm 7.96 \mathrm{pd}$ (range 4 to 35 ) and $17 \pm 6.93 \mathrm{pd}$ (range 6 to 35 ) for the control group. There was no statistically significant difference between the groups $(p=0.40)$.

The mean base out to break at near (BOBN) for 


\section{$\square$ Dyslexic $\square$ Control}

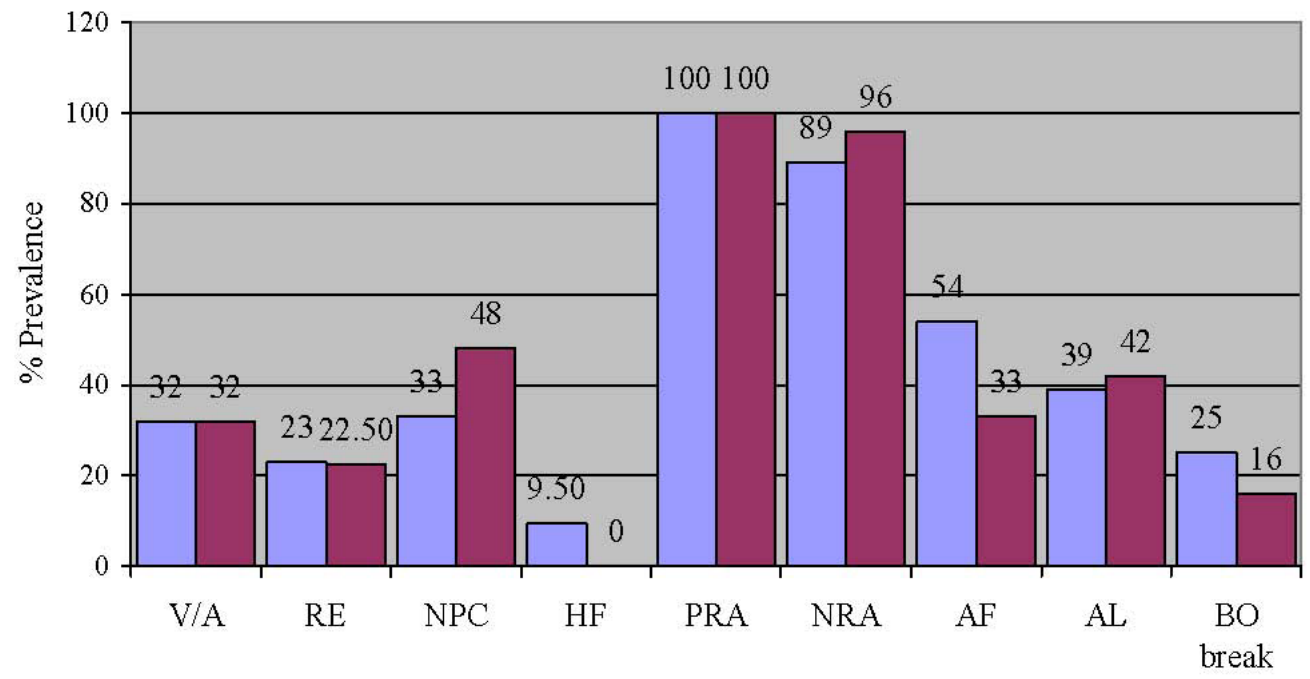

Prevalence of vision variables tested

Figure 3. Comparison of the percentage prevalence of all the vision variables examined between the dyslexic and control groups as defined in Table 1. VA=visual acuity, $\mathrm{RE}=$ refractive errors, $\mathrm{HF}=$ heterophoria, $\mathrm{NPC}=$ near point of convergence, $\mathrm{PRA}=$ positive relative accommodation, $\mathrm{NRA}=$ negative relative accommodation, $\mathrm{AF}=$ accommodative facility, $\mathrm{AL}=$ accommodative lag, $\mathrm{BO}$ break $=$ base out to break at near. The prevalence of remote NPC $(>10 \mathrm{~cm})$ was significantly higher in the control group than in the dyslexic group whereas the prevalence of poor accommodative facility was significantly higher in the dyslexic than in the control group.

the dyslexic group was $21.60 \pm 11.62 \mathrm{pd}$ (range 8 to 40 ) and $21.09 \pm 8.42 \mathrm{pd}$ (range 10 to 40 ) for the control group. There was no statistically significant difference between the two groups $(p=0.84)$. The mean base out to recovery at near for the dyslexic group was $13.35 \pm 7.45 \mathrm{pd}$ (range 6 to 35 ) and $15.55 \pm 6.25$ pd (range 8 to 30 ) for the control group. There was no statistically significant difference between the two groups $(p=0.16)$.

Based on the recommended norm of 30-40 pd for base out break (fusional amplitude) at near documented by Bishop ${ }^{22}$ and Mellville and Firth ${ }^{24}$, the prevalence of poor positive fusional amplitude at near was $16 \%$ for the control and $25 \%$ for the dyslexic group.

\section{Discussion}

This study compared the prevalence of vision defects in dyslexic and a control group of non-dyslexic schoolchildren. It was hypothesized that the dyslexic participants would not have a higher prevalence of vision defects than the control group but only the results for the binocular accommodative facility did not support our hypothesis as the binocular accommodation facility at near was significantly greater in the dyslexic than the control group ( $p=0.027)$.

The prevalence of visual acuity worse than $6 / 9$
$(32 \%)$ was the same for both groups and there was no statistically significant differences (RE, $p=0.29$, LE, $p=0.23)$. Two participants who had visual acuities of $6 / 60$ had cataracts while $23 \%$ of the dyslexic and $22.5 \%$ of the control group had refractive errors. These findings suggest that the reduced visual acuities in these populations are more related to refractive errors and corroborates the reports that visual acuity defects in paediatric populations are more related to refractive error changes in the population rather than ocular diseases ${ }^{17}$.

Similar to the VA findings, there was no statistically significant difference in the prevalence of uncorrected refractive error between both groups. These findings indicate that the dyslexic participants are not more at risk of a particular refractive anomaly compared to the participants from the control group. The high prevalence of the total refractive errors (especially astigmatism from both groups) highlights the need for regular vision screening in schoolchildren in South Africa. Our findings of a similar distribution of refractive errors and a lack of statistically significant difference between the dyslexic and control group corresponds with the findings on total refractive errors reported by Evans et $a l^{4}$ and Ygge et al ${ }^{13}$. More so, the mean spherical equivalent refractions (SER) val- 
ues (dyslexic group: RE 0.86 D, LE 0.57 D. Control group: RE $0.70 \mathrm{D}, \mathrm{LE}, 0.49 \mathrm{D})$ found in the present study lies within the normative refractive status value ( -0.50 to 1.25 and within SD 1) documented by Walters35, and is comparable to the mean SER of $0.77 \mathrm{D}$ for the (right and left eye were similar) reported by Evans et al 36 and RE $0.83 \pm 1.06$ and LE $0.89 \pm 1.23$ ) reported by Gronlund et a 27 .

The prevalence of myopia $(6.5 \%)$ was similar for both groups. This corresponds with the $6 \%$ prevalence reported by Gronlund et al ${ }^{27}$. In contrast, Alvarez et $a l^{37}$ found that $5.7 \%$ of the poor readers had myopia compared to $19.4 \%$ of the control group. As there was no information on the refractive status of dyslexic children in South Africa, we have attempted to relate our findings to studies, which investigated the refractive status of mainstream schoolchildren in South Africa conducted by Naidoo et al ${ }^{38}$ and Mabaso et $a l^{39}$. Naidoo et $a l^{38}$ reported a $2.9 \%$ prevalence of myopia whereas in the study by Mabaso et al ${ }^{39}$ the prevalence of myopia was $2.5 \%$.

Hyperopia was more prevalent $(6.5 \%)$ among the dyslexic group than in the control group (3\%). Two children had latent hyperopia (based on the assumption that increased plus did not blur the distance vision). The full magnitude of the hyperopic findings could not be estimated because cycloplegia was not used. Therefore, it is possible that the prevalence of hyperopia may have been under-estimated. It has been established that the use of cycloplegia in refraction reveals the full extent of hyperopia ${ }^{21,40,41}$ and that up to a mean of 0.64 DS more plus can be expected, using cycloplegic refraction ${ }^{21}$. In the study by Alvarez et $a l^{37}, 28 \%$ of the children with reading difficulties were hyperopic compared to $16 \%$ of the control group. Gronlund et a ${ }^{27}$ reported a 9\% prevalence of hyperopia (using cycloplegia). Our findings on hyperopia are therefore more comparable to the values reported by Gronlund et al27, however, the validity of this comparison is limited by the non-use of cyloplegia in the present study. Although Mabaso et $a^{139}$ assessed refractive errors without cycloplegia and used the same definition of hyperopia $(\geq 0.75 \mathrm{D})$ as in the present study but reported a $73.1 \%$ prevalence of hyperopia. It is not clear why there was such a marked difference in the prevalence of hyperopia between the two studies. In contrast, Naidoo et al ${ }^{39}$ reported a $1.8 \%$ prevalence of hyperopia, which is lower than the prevalence in the present study. Given that ethnic origins, culture and socio-economic class are comparable between the study by Naidoo et al38, Mabaso et $a^{339}$ and the present study, the difference in prevalence of hyperopia between the study by Naidoo et $a l^{38}$ and the present study is more related to the different criteria used to define hyperopia in both studies. Naidoo et $a l^{38}$ defined hyperopia as $\geq 2 \mathrm{D}$. The criteria used to define a variable greatly influence the prevalence rate 27,42 .

In relation to reading, simple to moderate hyperopia may not cause constant blur at a distance or near point, but the extra accommodative effort produces asthenopic symptoms of intermittent blur, headache, fatigue, and inattention in some patients, which may be mistaken for short attention span. Uncorrected hyperopia is associated with esophoria at near point, which can stress the fusional vergence systems that hold the eyes in correct alignment. If the hyperopia and esophoria is excessive, an accommodative esotropia can result 43,44 .

The prevalence of astigmatism was the highest of the refractive errors and was more prevalent in the control group (13\%) than in the dyslexic group (10\%). This result is in contrast to the findings by Latvala et $a l^{8}$ and Ygge et $a l^{13}$. The prevalence of astigmatism (defined as $\geq 0.75 \mathrm{D}$ ) reported by Naidoo et al ${ }^{38}$ were RE: $6.7 \%$ and LE: $6.8 \%$. In the study by Mabaso et $a l^{39}, 31.3 \%$ of the participants were astigmatic (defined as $\geq-0.25 \mathrm{D}$ ). The difference in prevalence reported between the present study and the study by Mabaso et $a l^{39}$ may be due to the differences in the criteria used to classify astigmatism. Astigmatism affects vision and reading in different ways. Clinically, astigmatism over $1.50 \mathrm{D}$ can often cause severe eyestrain and interfere with reading. Even lesser degrees of astigmatism can be symptomatic in some patients ${ }^{43}$.

Anisometropia is of great clinical interest because of its association with strabismus and amblyopia 45,46 . The prevalence of anisometropia was similar $(6.5 \%)$ in both groups. This is comparable to results $(3.6 \%$ from dyslexic group and $6 \%$ from the control group) reported by Latvala et $a l^{8}$. The prevalence of anisometropia was not reported in several studies ${ }^{4-7,9-15}$ on dyslexic populations. In anisometropia, the difference in refraction as well as the refractive error causes the image to be out of focus on one retina, blunting the development of the visual pathway in the affected eye ${ }^{45}$. In 
relation to reading dysfunction, anisometropia causes poor reading skills probably through the mechanism of poor sensory and motor fusion rather than reduced visual acuity. It degrades binocular coordination and consequently reduces visual comfort and efficiency if the binocular coordination is under stress ${ }^{44}$.

Two participants $(6.5 \%)$ from the dyslexic group had amblyopia due to cataracts whereas none had amblyopia from the control group. Cataract is a major cause of amblyopia (deprivation amblyopia) by causing an impediment to the visual axis ${ }^{45}$. Our result is comparable to the findings by Latvala et al ${ }^{8}$ who reported the prevalence of amblyopia in the dyslexic group to be $3.6 \%$ as compared to the control group with no amblyopia. The prevalence of amblyopia was not reported in several studies s-7, 9-15 $^{\text {on dyslexic pop- }}$ ulations.

Refractive errors in general are among the leading causes of visual impairment worldwide and are responsible for high rates of visual impairment ${ }^{47}$. Schoolchildren are particularly a high-risk group because uncorrected refractive errors can affect their learning abilities as well as their physical and mental development ${ }^{47}$. Variations in results on RE reported in different studies may be due to differences in the type of demographics studied, classification criteria, and the use of cycloplegia to assess refractive errors $27,33,47$.

The prevalence of a remote near point of convergence $(>10 \mathrm{~cm})$ was significantly higher in the control than in the dyslexic group. In contrast, Latvala et $a l^{8}$ reported that the dyslexics had more remote NPC than the control group. A possible explanation for the finding in the present study is that children who do not have reading difficulties may be more comfortable when reading and tend to read more often than children who do. Consequently, with an increasing ability to read, there is likely to be more demand on accommodation and convergence resulting in near point stress. More so, Owens and Wolf-Kelly 48 found that near work induces a recession of the near point of accommodation or vergences and that it is a potential source of visual problems. Furthermore, as a remote near point of convergence is a hallmark sign in the diagnosis of convergence insufficiency ${ }^{49}$, a more receded NPC suggests that the participants from the control group are more prone to developing convergence insufficiency. More so, Chen et al ${ }^{50}$ studied NPC in children aged 1-17 years and reported that an increasing incidence of remote NPC with increasing age in their study might be due to the near work demands of primary school which might create a different level of near point stress than the near work conditions in preprimary school years. Consequently, an alternative explanation for the lack of association between dyslexia and NPC in the present study can be inferred; if near point task induces a recession of NPC ${ }^{48}$, dyslexic participants who are more averted to reading would perform better in near point of convergence testing.

In the present study, all participants were orthophoric at distance and as reported in other studies $7,51,52$. The major finding on heterophoria in this study is a higher prevalence $(9.5 \%)$ of exophoria at near in the dyslexic participants, than in the control group that had no exophoria A higher prevalence of heterophoria would mean that the dyslexic participants may be more uncomfortable when doing near work. According to von Noorden (cited by Kommerell et al) ${ }^{53}$ heterophoria typically causes asthenopia. Patients with asthenopic symptoms often have an aversion to reading. Typically, such complaints tend to be less severe or to disappear when patients do not use their eyes in close work $^{53}$. Similar to the present study, Latvala et al ${ }^{8}$ and Evans et $a l^{7}$ assessed near horizontal heterophoria using the cover test and the Maddox Wing. Our findings of a higher prevalence of near exophoria in the dyslexics than in the control group is consistent with reports by Latvala et $a l^{8}$ and our findings of a lack of statistically significant difference in near heterophoria is consistent with reports by Evans et al7 and Bucci et al ${ }^{12}$.

The dyslexic group had a marginally reduced monocular amplitude of accommodation compared to the control group and there was no statistically significant difference between the two groups $(p=0.70)$. This result corroborates reports by other authors $6,7,11,37$. Monocular amplitude measures are particularly important to determine whether a patient has accommodative insufficiency (AI) ${ }^{54}$ and AI has been reported to be a common cause of asthenopia in school children between the ages of eight and 15 years ${ }^{55}$. The symptoms of accommodation insufficiency are specifically related to near vision work ${ }^{56}$.

The prevalence of poor binocular accommodative facility was significantly higher in the dyslexic than in the control group ( $p=0.027$ ) which suggests that the 
dyslexics have poorer accommodative facility than the control participants. Inadequate accommodative facility have been associated with symptoms related to near point asthenopia ${ }^{57}$ which suggests that the dyslexic child will be affected when readng. However, a lack of symptom inventory in this study precludes a firm conclusion on the relationship between accommodative infacility and symptoms. Furthermore, the subjective nature of the accommodative facility testing makes it difficult to draw a firm conclusion on the clinical relevance of the statistical significant association between dyslexia and accommodative infacility found in this study. This result however, is similar to findings in other studies $7,15,37$ which reported that dyslexics appeared to have weaker accommodative facility. Furthermore, Keily et al ${ }^{15}$ reported that $36.7 \%$ of the dyslexic and $27.2 \%$ of the control group failed the accommodative facility tests. In the present study, $33 \%$ of the participants from the control group failed the AF test. This finding is more comparable to the reports by Moodley58, which reported a 33\% prevalence of poor AF in a population of schoolchildren in Durban, South Africa. In contrast, Buzzelli ${ }^{5}$ reported that the dyslexic group had a better AF than the control group. The differences in the results between the present study and the study by Buzzelli ${ }^{5}$ may due to the differences in technique; Buzzelli ${ }^{5}$ assessed AF using the Bernell Vectogram with polarized target for suppression control whereas the flipper technique, without control for suppression was used in the present study. Binocular accommodation facility results vary depending on whether or not suppression has been monitored while testing 59,60 . Other variables that may affect accommodative facility rates are: test distance, letter size and flipper lens power ${ }^{60}$.

During near tasks, the eyes are not usually precisely focussed on the object of regard, but the accommodation lags a small amount behind the target ${ }^{61,62}$. There was no statistically significant difference between both groups in accommodation lag (RE, $p=0.83$, and LE, $p=0.61$ ). Similarly, Evans et al7 found no statistically significant difference between the two groups ( $p>0.68$, unpaired $t$ test). Evans et $a^{36}$ also reported a mean accommodation lag of $1.12 \mathrm{D}$, which is comparable to our mean findings of: RE: $0.91 \pm 0.38 \mathrm{D}$ and $0.92 \pm 0.57 \mathrm{D}$ for the dyslexic and control groups respectively. Furthermore, our mean values are within the normal range determined by Rouse and Hutter
$(0.75 \pm 1.00 \mathrm{D})^{63}$. In the present study, $42 \%$ of the participants from the control group (mean age 11.75 years) had lag of accommodation, which is in contrasts with the $27 \%$ prevalence reported by Moodley ${ }^{58}$. The mean age of the participants in the study by Moodley ${ }^{58}$ was 9.38 years. The difference in the prevalence reported in the two studies may be related to the difference in the ages of the participants in both studies. Rouse and Hutter ${ }^{63}$ noted that the MEM mean values increases with both age and school grade.

Accommodation accuracy relates to reading in different ways. An efficient accommodation posture is important in the reading process as an individual with a lag of accommodation habitually under-accommodates which may result to asthenopia and difficulty with reading. An accommodative response that manifests as an excessive lag of accommodation may indicate latent hyperopia, esophoria, or may be associated with accommodative insufficiency, or accommodative spasm ${ }^{62}$. In this study, the prevalence of high lag in the dyslexic group may be related to the prevalence of latent hyperopia, poor negative vergences and esophoria.

The relative accommodation (also an indirect assessment of the vergence system) assesses patients' ability to increase and decrease accommodation under binocular conditions when the total convergence demand is constant ${ }^{23}$. The results for the relative accommodation for all the participants from both dyslexic and control groups were unexpectedly high although the difference between the two groups was non-significant. Similarly, high RA values (NRA, 3.25, PRA -3.90 ) was reported by Chen et a ${ }^{26}$ although the technique used to assess RA was not indicated. In contrast, Álvarez and Puell's ${ }^{37}$ findings were within normative values $(2 \text { and }-2)^{19,31}$. The difference in the results between Alvarez and Puell ${ }^{37}$ and the present study may be due to the difference in technique. Alvarez and Puell ${ }^{37}$ assessed RA using the phoropter whereas the trial lenses were used in the present study (given the study setting). The phoropter has been reported to give a more reliable result for RA ${ }^{23}$. Another possible explanation for high RA is that high NRA can be associated with disorders such as accommodative insufficiency and convergence excess whereas high values of PRA are related to anomalies in which accommodative excess appears $^{31}$. Furthermore, a high value of the NRA may also mean that the refraction 
may have been under corrected for hyperopia or over corrected for myopia ${ }^{31}$ and high NRA may also be due to excessive accommodation ${ }^{20}$.

Generally, an inefficient accommodation function may lead to difficulties in reading as the focusing system of the eyes play a major role in the reading process ${ }^{37}$. Children who suffer some anomalies of accommodation are more prone to visual fatigue ${ }^{64}$. Furthermore, dysfunctions of accommodation can significantly interfere with the comfort, clarity, speed and accuracy of reading as the child develops reading skills ${ }^{65}$.

For fusional reserves, the participants from both groups either could not report or understand blur therefore the result for break and recovery was used in the analysis of all aspects of fusional reserves as in other studies ${ }^{7,34}$. Furthermore, only the findings for the near PFV are emphasized in this report as the PFV (measures convergence ability) are more important in assessing reading dysfunction and near measurements are more relevant in assessing vision functions in dyslexic children 23,66 . The prevalence of poor positive fusional amplitude at near was $16 \%$ for the control and 25\% for the dyslexic group. Grisham et al67 reported that $38 \%$ of their study population of poor readers had break values of $<18$ pd whereas in the study by Latvala et $a^{8}$ the prevalence of fusional amplitude (using referral criteria of $\geq 32 \mathrm{pd}$ at a distance of $33 \mathrm{~cm}$ ) was $6.1 \%$ for the control group and $7.5 \%$ for the dyslexic group. At near, a testing distance of $40 \mathrm{~cm}$ was used in the present study. The difference in prevalence between the present study and the study by Latvala $e t l^{8}$ may be related to the different test distances used.

In the present study, six participants from the dyslexic group and two from the control group had base out to break values of over $40 \mathrm{pd}$. Wesson et al ${ }^{25}$ reported a similar finding. The high base out to break values in the present study may be due to a lack of suppression control in assessing the fusional reserves. According to Wesson et al ${ }^{25}$ when suppression is controlled, the average vergence values will be lower because the test is stopped when the suppression is detected. If suppression is not monitored, the break is not detected until the stimulus is outside the suppression zone and a higher vergence value is obtained ${ }^{25}$. Another possible explanation for an unexpectedly high base out finding is that exophoric conditions make compensating for base out more difficult than base in testing ${ }^{35}$. It is not clear if this is the case in the present study although the prevalence of exophoria at near was $9.5 \%$.

Statistically, at near, the base out break and recovery was similar for both groups in the present study although lower than the normative values (Break $23 \pm$ $8 \mathrm{pd}$, Recovery $16 \pm 6 \mathrm{pd}$ ) determined by Scheiman et $a l^{34}$. Reduced break or recovery findings indicate the presence of near point stress ${ }^{68}$. Evans et al ${ }^{7}$ reported a mean base out to break value of $15.4 \pm 6.7 \mathrm{pd}$ ) for the dyslexic group and $19 \pm 7.8 \mathrm{pd}$ ) for the control with a statistically significant difference $(p=0.03)$. Ygge et $a l^{11}$ reported that at near, the mean fusional convergence (break values) were 26.5 \pm 6.8 ) for the dyslexics and $26.7 \pm 7.2 \mathrm{pd}$ ) for the control and there was no statistically significant difference between the two groups $(p=0.75)$. Goulandris et al found no significant differences between the two groups in any aspect of fusional reserves measurement. Chen and Abidin $^{26}$ reported PFV mean break values of $23 \pm 8$ pd) at near for children aged 7-12 years. The findings of the present study, although lower, is more comparable to the results by Ygge et al ${ }^{11}$, Chen and Abidin ${ }^{26}$ and Goulandris et $a l^{6}$ but higher than the values reported by Evans et al7. The difference in results in these studies $6,7,11,26$ may be because rotary prisms were used in the study by Evans et al ${ }^{7}$ whereas prism bars was used in the studies by Chen and Abidin ${ }^{26}$, Ygge et $a l^{11}$ and the present study. Several studies ${ }^{25}$, 34, 69 have demonstrated that fusional reserves measurements using either smooth (rotary prisms) or step (prism bars) give different results; Ciuffreda et a ${ }^{70}$ reported that the mean $\mathrm{BO}$ break at near averages measured with prism bar were higher (by 4 to $8.7 \mathrm{pd}$ ) than values obtained using the phoropter in a study on near vergence ranges variability. Furthermore, the high standard deviations in the present study and the studies cited $6,7,11,26$ on fusional reserves indicate a high variability in the fusional reserves measurements. Fusional reserves can be inconsistent and less reliable in children unless strict control measures are applied $25,34,71$. Inter-examiner variation can be as large as 10 to $16 \mathrm{pd}$ and intra-examiner differences can be as large as $12 \mathrm{pd}^{71}$. Other factors that affect vergence reserve measurements include test target and lighting conditions ${ }^{25}$.

Fusional vergence amplitudes reflect the ability of 
the oculomotor system to maintain sensory fusion in spite of varying vergence requirements ${ }^{72}$. Vergence amplitudes provide information about a patient's ability to maintain comfortable binocular vision ${ }^{22}$. The symptoms associated with deficiencies in the vergence system include letters or words appearing to float or move around, postural changes noted when working at a desk, difficulty aligning columns of numbers, intermittent diplopia at either distance or near ${ }^{73}$. Again, we are unable to associate these symptoms with our data as symptoms inventory was not part of this study.

\section{Significance, Limitations, and Recommendations}

This study has relevance in South Africa in enhancing our understandings of the visual status of dyslexic schoolchildren especially in a Black population in South Africa, which has received limited research attention. Secondly, the information obtained will assist policy makers, educators, school nurses, psychologists as well as optometrists in making informed decisions on the visual characteristics of dyslexic children. Thirdly, this study highlights some methodological issues inherent in assessing visual functions in dyslexic schoolchildren.

The limitations in the study, which may affect the generalization of the findings, include relatively small sample size, refractive error was assessed without the use of cycloplegia and the assessment of relative accommodation using trial lenses. Suppression was not monitored during some binocular procedures and possibly should have been.

It is recommended that future studies (i) be randomised using large sample size (ii) assess refractive error under cycloplegia (iii) assess accommodative facility and fusional reserves using suppression control (iv) assess relative accommodation using the phoropter.

\section{Conclusion}

The data from this study shows that the prevalence of vision defects was similar between the dyslexic and non-dyslexic participants which suggest that an association between dyslexia and the vision variables investigated can not be inferred. Only poor binocular accommodation facility at near was significantly more prevalent in the dyslexic than the control group. However, due to the small sample size, this statisti- cally significant difference may not imply clinical relevance. Dyslexia is a mild neurological disorder of which one sign is motor dysfunction such as eye movement disorder ${ }^{5}$. More complex vision functions such as eye movements may be more related to dyslexia than peripheral functions (such as visual acuity, refraction, near point of convergence, accommodation functions and fusional reserves). Further research in this area is thus warranted.

The data obtained in this study has clinical relevance and implications for the assessment, detection and management of vision anomalies in dyslexic schoolchildren.

\section{Acknowledgement}

We are grateful to Mr Percy Mashige of the University of KwaZulu-Natal for very valuable suggestions and Lawrence Sithole of the University of South Africa for useful comments. We also thank the participants of this study and their parents for their cooperation.

\section{References}

1. Allen P, Evans BJ, Wilkins A. Specific learning difficulties and vision. Optometry Today 2009 January 30 30-38.

2. Shaywitz SE. Dyslexia. N Engl J Med 1998338 307-312.

3. Scheiman M, Rouse M. Optometric Management of Learning Related Vision Problems. Missouri: Mosby, 1994.

4. Evans BJ, Drasdo N, Richards IL. Investigation of some sensory and refractive visual factors in dyslexia. Vis Res 1994 34 1913-1926.

5. Buzelli AR. Stereopsis, accommodative and vergence facility. Do they relate to dyslexia? Optom Vis Sci 199168 842846.

6. Goulandris L, McIntyre A, Snowling M, Bethel J, Lee J. A comparison of dyslexic and normal readers using orthoptic assessment procedures. Dyslexia 19984 30-48.

7. Evans BJ, Drasdo N, Richards I. Investigation of accommodative and binocular functions in dyslexia. Ophthal Physiol Opt 199414 5-18.

8. Latvala ML, Korhoenen TT, Penttinen M. Ophthalmic findings in dyslexic schoolchildren. Br J Ophthalmol 199478 339-343.

9. Aasved H. Ophthalmological status of schoolchildren with dyslexia. Eye 1987 1 61-68.

10. Kapoula Z, Bucci M, Jurion F. Evidence for frequent divergence impairment in French dyslexic children: Deficit of convergence relaxation or of divergence per se? Graefes Arch Clin Exp Ophthalmol 2007245 931-936.

11. Ygge J, Lennerstarnd G, Rydberg A, Wijecoon S, Petterson BM. Oculomotor functions in a Swedish population of dys- 
lexic and normally reading children. Acta Ophthalmol (Copen) 199371 10-21.

12. Bucci M, Gignac D, Kapoula Z. Poor binocular coordination of saccades in dyslexic children. Graefe's Arch Clin Exp Ophthalmol 2008246 417-428.

13. Ygge J, Lennerstarnd G, Axelsson I, Rydberg A. Visual function in a Swedish population of dyslexic and normally reading children. Acta Ophthalmol (Copen) 199371 1-9.

14. Stein JF, Riddell PM, Fowler S. Disordered vergence control in dyslexic children. Br J Ophthalmol 198872 162-166.

15. Keily PM, Crewther SG, Crewther DP. Is there an association between functional vision and learning? Clin Exp Optom 200184 346-353.

16. Wajuihian SO, Naidoo KS. Visual factors and dyslexia: A Research Review. S Afr Optom 201069 58-68.

17. Eskridge JB, Amos JF, Bartlett JD. Clinical Procedures in Optometry. New York: JP Lippicott Company, 1991.

18. Carlson NB, Kurtz D. Clinical Procedures in Ocular Examination. New York: McGraw Hill Professional Publishers, 2004.

19. Grosvenor T. Primary Care Optometry. Philadelphia: Butterworth Heinemann Elsevier, 2007.

20. Elliot D, Flanagan J, Hrynchak P, Prokopich L, Winn B. Clinical Procedures in Primary Eye Care. Oxford: Butterworth Heinemann, 2003.

21. Lowery JP, Joachim A, Olson R, Peel J, Pearce N. Autorefraction Vs. Retinoscopy. A comparison of non-cycloplegic measures in a pediatric sample. J Behav Optom 200516 38.

22. Bishop A. Convergence and convergent fusional reservesinvestigation and treatment. Optician 1999218 20-24.

23. Eperjesi F. Optometric assessment and management in dyslexia. Optometry Today 2000 December 15 20-25.

24. Melville AC, Firth AY. Is there a relationship between prism fusion range and vergence facility? Br Orthopt J 200259 38-44.

25. Wesson MD, Massen LC, Boyles ST. Objective testing of vergence ranges. J Am Optom Assoc 199566 338-342.

26. Chen AH, Abidin AHZ. Vergence and acommodation systems in Malay primary school children. J Biomed Sci 2002 9 9-15.

27. Grönlund MA, Anderson S, Aring E Anna-Lena Hard, Hellstrom. Ophthalmological findings in a sample of Swedish children aged 4-15 years. Acta Ophthalmol Scand 200684 169-176.

28. Dwyer P, Wick B. The influence of refractive correction upon disorders of vergence and accommodation. Optom Vis Sci 199572 224-232.

29. Hayes GJ, Cohen BE, Rouse MW, De Land PN. Normative values for the near point of convergence of elementary schoolchildren. Optom Vis Sci 199875 506-512.

30. Zellers JA, Alpert TL, Rouse MW. A review of the literature and normative study of accommodative facility. $J \mathrm{Am} \mathrm{Op}$ tom Assoc 198455 31-37.

31. Garcia AC, Francisco LP. Evaluating relative accommodation in general binocular function. Optom Vis Sci 200279 779-787.

32. Dwyer P. Prevalence of vergence accommodation disorders in a school-age population. Clin Exp Optom 199275 1018.

33. Grönlund MA, Aring E, Hellström A, Landgren M, Strömland K. Visual and ocular findings in children adopted from eastern europe. $\mathrm{Br} J$ Ophthalmol 200488 1362-1367.

34. Scheiman M, Herzberg H, Franz K, Margolies M. A normative study of step vergences in elementary schoolchildren. J Am Optom Assoc 198960 276-280.

35. Walters J. Portsea modified clinical technique: Results from an expanded optometric screening protocol for children. Aust J Optom 198467 176-18.

36. Evans BJ, Drasdo N, Richards, IL. An investigation of the optometric correlates of reading disability. Clin Exp Optom 199275 192-200.

37. Álvarez C, Puell MC. Accommodative functions in schoolchildren with reading difficulties. Graefe's Arch Clin Exp Ophthalmol 2008246 1769-1774.

38. Naidoo KS, Raghunandan A, Mashige P. Refractive error and visual impairments in African children in South Africa. Invest Ophthal Vis Sci 200344 3764-3770.

39. Mabaso RG, Oduntan AO, Mpolokeng MBL. Refractive sta $\neg$ tus of primary school children in Mopani district Limpopo Province, South Africa. S Afr Optom 200665 125133.

40. Rotsos T, Grigoriou D. Kokkolaki A, Manios N. A comparison of manifest refractions, cycloplegic refractions and retinoscopy on the RMA-3000 autorefractometer in children aged 3 to 15 years. Clin Ophthalmol 20093 429431.

41. Williams C, Northstone K, Howard M, Harvey I. Prevalence and risk factors for common vision problems in children: Data from the ALSPAC Study. Br J Ophthalmol 200892 959-964.

42. Bennett GR, Blondin M, Ruskiewics J. Incidence and prevalence of selected visual conditions. J Am Optom Assoc $1982 \mathbf{5 3}$ 647-656.

43. Solan HA. Learning disabilities In: Rosenbloom AA, Morgan MW. Principles and Practice of Pediatric Optometry. New York: JP Lippincott, 1990.

44. Grisham JD, Simons HD. Perspective on Learning Disabilities: In Rosenbloom A, Morgan MW. Principles and Practice of Pediatric Optometry New York: JP Lippincott, 1990.

45. Doshi NR, Rodriguez MF. Amblyopia. Am Fam Physician 200775 361-367.

46. Xue-Jiao Qin, Tom H. Margrain, Chi Ho To, Nathan, B Guggenheim .JA Anisometropia is independently associated with both spherical and cylindrical ametropia. Invest Ophthl Vis Sci 200546 4024-4031.

47. Fotouhi A, Hashemi H, Khabazkhoob H, Kazem M. The prevalence of refractive errors among schoolchildren in Dezful, Iran. Br J Ophthalmol 200791 287-292.

48. Owens DA, Wolf-Kelly K. Near work, visual fatigue, and variations of oculomotor tonus. Invest Ophth Vis Sci 1987 28 743-749.

49. White T, Major A. A comparison of subjects with convergence insufficiency and subjects with normal binocular vision. J Behav Optom 200415 37-41. 
50. Chen HA, Daniel L, Howell ER. Near visual function in young children. Part 1: Near point of convergence. Ophthal Physiol Opt 200020 185-198.

51. Walline J, Mutti D, Zadnik K, Jones L. Development of phoria in children. Optom Vis Sci 199875 605-610.

52. Mathebula SD, Sheni DD, Oduntan AO. Heterophoria measurement in children S Afr Optom 200362 99-103.

53. Kommerell G, Gerling J, Ball M, Paz H, Bach M. Heterophoria and fixation disparity: a review. Strabismus 20008 127-134.

54. Sterner B, Gellerstedt M, Sjostrom A. The amplitude of accommodation in 6 to 10-year-old children-not as good as expected. Ophthal Physiol Opt 200424 246-251.

55. Borsting E, Rouse MW, Deland PN, Hovett S, Kimura D, Park M, Stephens B. Association of symptoms and convergence and accommodative insufficiency in school-age children. Optometry 200374 25-34.

56. Abdi S, Brautaset R, Rydberg A, Pansell T. The influence of accommodative insufficiency on reading. Clin Exp Optom $20079036-43$.

57. Siderov J. Improving interactive facility with vision training Clin Exp Optom I990 73 128-131.

58. Moodley VR. Amplitude, facility and accuracy of accommodation in a primary school population. $S$ Afr Optom 200867 147-154.

59. Siderov J, Johnston AW. The importance of the test parameters in the clinical assessment of accommodation facility. Optom Vis Sci 199067 551-557.

60. Loerzel R, Tran L, Goss DA. Effect of lens power on binocular lens flipper accommodative facility rates. J Behav Optom 200314 7-9.

61. Evans BJ. Visual factors in dyslexia. In: Turner M, Rack J. The Study of Dyslexia. New York: Kluwer Academic Press, 2004.

62. Antona B, Sanchez I, Barrio A, Barra F, Gonzalez E. Intra-examiner repeatability and agreement in accommodative response measurements. Ophthal Physiol Opt 200929 606-614.

63. Rouse MW, Hunter RF, Shifter R. A normative study of the accommodative lag in elementary schoolchildren. Am J Optom Physiol Opt 198461 693-697.

64. Baraas RC, Demberg A. The prevalence of optometric anomalies and symptoms in children receiving special tuition. Ophthal Physiol Opt 199919 68-73.

65. Leslie S. The optometrist's role in learning difficulties and dyslexia. Clin Exp Optom 200487 1-3.

66. Evans BJ. Role of optometrist in dyslexia Part 2. Optometric correlates of dyslexia. Optometry Today 2004 February 27 35-41.

67. Grisham D, Powers M, Riles P. Visual skills of poor readers in high school. Optometry 200778 542-549.

68. Birnbaum M. Optometric Management of Near Point Vision Disorders. New York: Butterworth-Heinemam,1993.

69. Wesson MD. Normalization of the prism bar vergences. Am J Optom Physiol Opt 198259 628-634.

70. Ciuffreda M, Ciuffreda KJ, Wang B. Repeatability and variability of near vergence ranges. J Behav Optom 2006 $131-46$.
71. Rouse M, Borsting E, Deland D. Reliability of binocular vision measurements used in the classification of convergence insufficiency. Optom Vis Sci 200279 254-264.

72. Archer SM, Miller KK, Helveston EM, Ellis FD. Vergence amplitudes with Random-dot stereograms. $\mathrm{Br} J$ Ophthalmol 198670 718-723.

73. Hoffman LG, Rouse M. Referral recommendations for binocular function and/or developmental perceptual deficiencies. J Am Optom Assoc 198051 119-125. 